\title{
Physical factors at salt licks influenced the frequency of wildlife visitation in the Malaysian tropical rainforest
}

\author{
Nor Bazilah Razali ${ }^{1}$, Muhammad Syafiq Haiqal Shafie ${ }^{1}$, Rahaniza Ali Mohd Jobran ${ }^{1}$, \\ Nur Hayati Abdul Karim ${ }^{1}$, Shamsul Khamis ${ }^{1}$, Farah Shafawati Mohd-Taib ${ }^{1 *}$, \\ Shukor Md Nor ${ }^{1}$, Ehwan Ngadi², Siti Hajar Atiqah Razali ${ }^{3}$, Shahril Mod Husin ${ }^{4}$ and \\ Mohamed Shah Redza Hussein ${ }^{5}$
}

\begin{abstract}
${ }^{1}$ Department of Biological Sciences and Biotechnology, Faculty of Science and Technology, Universiti Kebangsaan Malaysia, Bangi, Selangor, Malaysia; ${ }^{2}$ Kolej GENIUS Insan, Universiti Sains Islam Malaysia, Nilai, Negeri Sembilan, Malaysia; ${ }^{3}$ Department of Wildlife and National Park Peninsular Malaysia, Kuala Lumpur, Malaysia; ${ }^{4} T N B$ Research Sdn Bhd, Kawasan Institusi Penyelidikan, Kajang, Selangor, Malaysia; ${ }^{5}$ Perbadanan Taman Negeri Perak, Gerik, Perak, Malaysia
\end{abstract}

Received for publication: 30 April 2020; Revision received: 26 October 2020; Accepted for publication: 4 December 2020.

\begin{abstract}
Mineral reservoirs or salt licks are commonly used by wildlife to regulate the concentration of salt and minerals in their bodies. Salt lick utilisation is known to be influenced by the chemical composition, but information on their physical properties, particularly vegetation surrounding the salt licks is scarce. In this study, physical factors and wildlife utilisation at two natural salt licks (SPU and SPS) located in Perak, Malaysia, were determined. Wildlife visitation data were retrieved from camera traps. SPU exhibits two reservoirs represented by rocky and clay substrate, with minimally dense vegetation dominated by hardwood species and climbers. SPS encompasses muddy topsoil, open canopy cover, with highly dense forest floor vegetation. The wildlife survey shows a higher frequency of visitation in SPS, especially by ungulates, potentially due to dense understorey foliage that provides foraging sites for these animals. SPU exhibits more diverse but less frequent wildlife species, particularly primates, carnivores, and avian groups. High emergence and closed canopy cover at this lick serve as perching sites for primates and birds, while less dense understory vegetation could aid in prey detection among carnivore. Regardless of their physical assemblages, salt licks are an essential local hotspot for wildlife, therefore, elucidating the need to prioritise conservation areas by maximising the complementarities of salt licks.
\end{abstract}

Key words: Natural salt licks; salt lick design; tropical rainforest; vegetation composition; wildlife visitation.

\section{Introduction}

Salt licks, locally known as sira or jenut, are mineral reservoirs visited by various wildlife species to regulate the concentration of salt and other essential minerals like zinc,

${ }^{*}$ Corresponding author. E-mail: farah_sh@ukm.edu.my
${ }^{\circ}$ Copyright: the Author(s), 2020 | Licensee PAGEPress, Italy 
magnesium, and calcium in their bodies. The behaviour of soil consumption (geophagy) and drinking water from the licks are typical in many animals, particularly mammals like the Ussuri moose and Alaskan moose (Tankersley and Gassaway 1983; Panichey et al. 2002), herbivores (Kreulen 1985), and even birds (Dudley et al. 2012). The behaviour is most readily observed in ungulates and primates, particularly herbivores, to compensate for the lack of sodium in their daily diet of plant tissues (Dudley et al. 2012; Gomez-Hovos et al. 2017). Salt licks are also widely recognised to attract a large number of wildlife species and can be considered hotspots of their own (Blake et al. 2011).

Studies are mainly focused on the characteristics of salt licks known to attract several species and individuals and to display the differences in salt lick usage by different species according to seasonal and temporal factors (Weeks 1978; Hon and Shibata 2013; Molina et al. 2014; Li et al. 2018). Factors influencing the preference and frequency of visitation to salt licks are related to the mineral composition, which varies during the dry or rainy season (Lizcano and Cavelier 2004), accessibility of the licks, and threat of predators (Tobler et al. 2009). In some cases, sexual differences also exist in the seasonal pattern of salt lick usage (Ping et al. 2011). A few studies focused on the chemical properties and composition of minerals utilised by a myriad of species and on the analysis of different mineral concentrations, such as sodium and potassium (Klaus et al. 1998; Sitienei et al. 2012). However, physical factors explaining the preferences and frequency of visitation of the animals to the salt licks are poorly documented.

The Royal Belum State Park (RBSP) is one of the oldest protected and pristine forest in Peninsular Malaysia. It is located at the northern tip of the main range of Banjaran Titiwangsa, which is the backbone of Peninsular Malaysia. RBSP hosts 12 natural salt licks, most of them are closely guarded, with only a few open to visitors. This study is particularly significant considering the impact that salt licks can have in terms of ecotourism (Chuan et al. 2012). An extensive look into the habitat, ecology, and distribution of salt licks in RBSP is almost non-existent, making this study the first of its kind to understand the physical properties and the existence in enriching the survival of wildlife.

Salt lick designs (slope, position, and location to nearest stream) and vegetation composition are hypothesised to influence the frequency of visitation by animals to the salt licks. We expected that each wildlife species would demonstrate its unique preferences on salt lick design and vegetation composition. Thus, the study aimed to investigate the physical characteristics of salt licks and how they affect the frequency of wildlife visitation. This study is crucial to provide a guideline for the construction of artificial salt licks.

\section{Study area}

Two salt licks within Royal Belum State Park were evaluated at the Sungai Papan area, identified as Sungai Papan Utara (SPU; X: 379428, Y: 623224) and Sungai Papan Selatan (SPS; X: 379490, Y: 622427; Figure 1). RBSP possesses a mean annual temperature of $24.2{ }^{\circ} \mathrm{C}$, rainfall of $240.46 \mathrm{~mm}$ yearly, and relative humidity of $96.6 \%$. These two sites are located 45 minutes away on a boat ride from the main jetty of the RBSP (Banding Jetty) and receive a relatively high number of tourists annually. The distance between these two salt licks is $805 \mathrm{~m}$. The SPU salt lick is located close to the riverbanks of Sungai Papan, with an elevation of $274 \mathrm{~m}$ above sea level and the size of $3 \mathrm{~m}^{2}$. It is easily accessible and can be reached in approximately 30 minutes on foot from the riverbanks of Sungai Papan. SPS, on the other hand, is located 30 minutes away on foot from the estuary of Sungai Papan, $176 \mathrm{~m}$ above sea level, with an area of $18 \mathrm{~m}^{2}$. Information regarding the macrohabitat, microhabitat, ecology, and distribution of salt lick in the Royal Belum forest reserve 
is scarce, and this is the first effort in understanding the properties and its significance in supporting wildlife at RBSP.

\section{Methods}

\section{The physical environment surrounding the salt licks}

The physical environment of the surrounding salt licks was thoroughly documented, including the slope, position, location to the nearest streams and any other observation deemed significant in the field. Any signs of disturbance were also recorded either from human or animal predators (e.g., tiger) that prevented other wildlife from visiting the salt licks. The location, position and slope of each salt lick was drawn schematically.

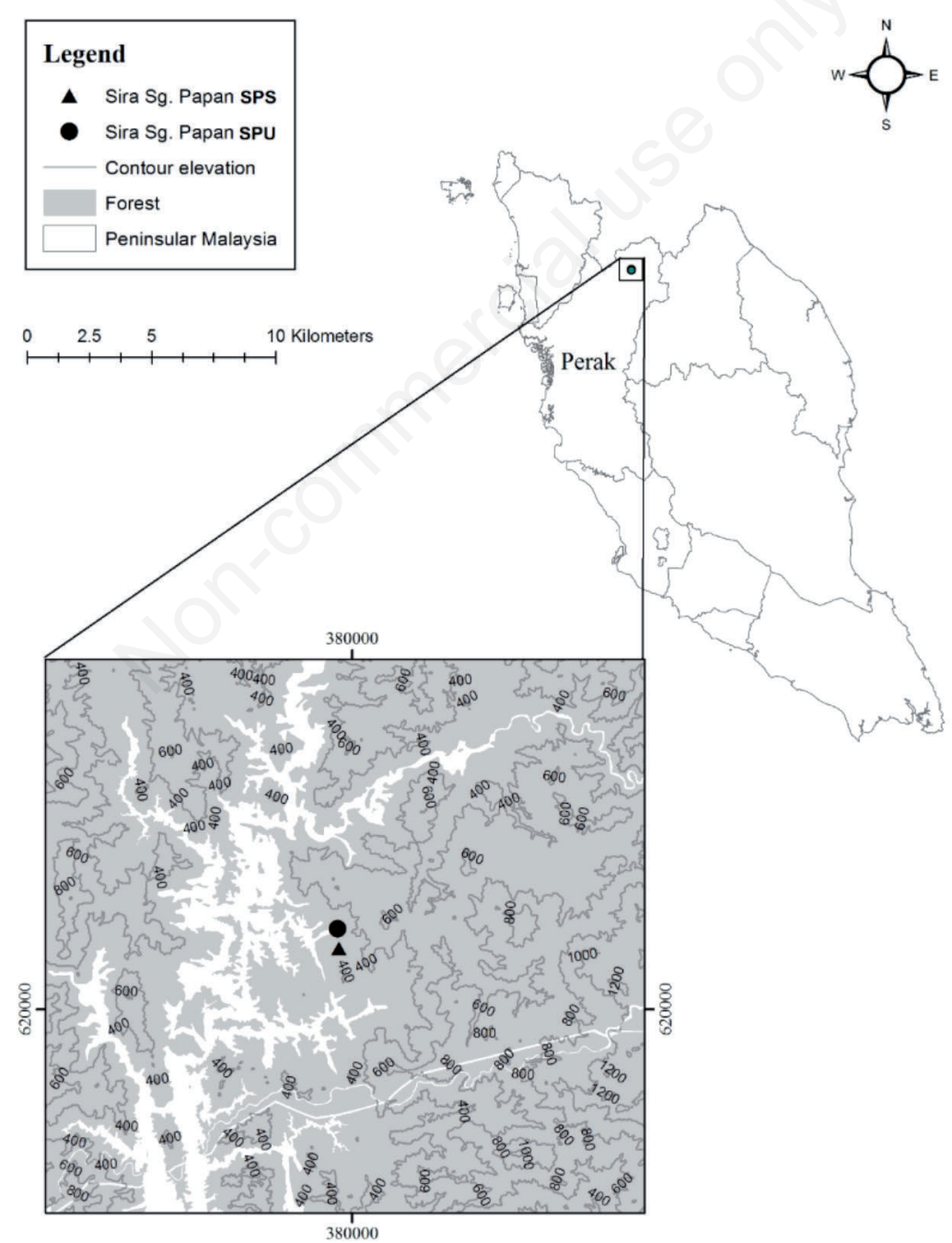

Figure 1. Map with the locations of both salt licks in RBSP. 


\section{Inventory of flora diversity at the salt licks}

An inventory of vegetation surrounding the salt licks was conducted to document the species presence, the location of the trees in relation to salt licks, and other plant groups. Flora survey was carried out in 4 subplots $(5 \mathrm{~m} \mathrm{x} 5 \mathrm{~m})$, totalling to $10 \mathrm{~m} \mathrm{x} 10 \mathrm{~m}$ plot. The plots were set in a way that positioned the salt licks in the middle of the plot. Trees with 1 $\mathrm{cm}$ and above breast height $(\mathrm{DBH})$ were measured, and other non-tree species were recorded by clump or individuals. All specimens were dried, identified, and deposited at UKMB Herbarium. Each plant species was measured for the diameter at breast height (DBH), identified to species level, and mapped according to the position of the salt licks. A list of plant species was generated for each salt licks, and diversity parameters were calculated. These species were assigned to different vegetation type (tree, small tree, shrub, herb, climber, palm, and fern) based on Turner (1995).

\section{Documentation of wildlife species}

The presence of wildlife at the salt licks were recorded using camera traps and direct and indirect observation in the field for rapid and non-invasive assessment of wildlife (De Bondi et al. 2010; Burton et al. 2015). Depending on the geography of the salt licks, two to three camera traps were installed facing the salt licks to document the occurrence and the number of visitations for each salt licks. Images were retrieved every month from February 2017 to August 2018. All camera traps were set to capture images in one-minute intervals. This is to allow the images captured in succession within one minute to be considered as the same individual, while the image that is noted sequential after the oneminute mark can be considered as different individuals. Images were identified and subsequently sorted out into their respective species groups using DigiKam software version 5.7.0-02 (DigiKam team 2019). This software was also programmed to estimate the frequency of visits by wildlife. Next, each species was assigned to specific feeding types, i.e., $\mathrm{HF}=$ herbivore-frugivore, $\mathrm{C}=$ carnivore, $\mathrm{O}=$ omnivore, $\mathrm{F}=$ frugivore, $\mathrm{I}=$ insectivore, and $\mathrm{G}=$ granivore, according to Francis (2008).

\section{Data analysis}

The frequency of wildlife visitation diversity and flora diversity were analysed using R software version 3.4.2 (R Core Team 2017) and Ecological Methodology version 7.2 (Informer Technologies Inc. 2019). A significance level of 95\% confidence interval or at probability $\mathrm{p}<0.05$ were set. Shannon's diversity index (H'), Simpson's diversity index (1-D), and the evenness index were used to measure the diversity of wildlife visiting each site. Assigning a value to the diversity of a site allows us to make a comparison based on the indices (Izsák and László 2000; Keylock 2005). Next, the comparison of wildlife visitation frequency and the frequency according to the feeding guilds were made between the two study sites. The normality test was performed prior to the analysis, and the outcomes of the Shapiro-Wilk test $(\mathrm{p}<0.05)$ indicated that data were not normally distributed; thus, non-parametric analyses were used. The Mann-Whitney U test was performed to compare wildlife visitation frequency and wildlife frequency according to feeding guilds of each species at both licks. A Principal Component Analysis (PCA) biplot was produced to distinguish the pattern of wildlife visitation based on their feeding types at different salt licks based on the first two axes, which represent the most variation. This analysis was performed using the PRIMER 7 version 7.0.13 (Quest Research Limited). 


\section{Results}

\section{Description of the design of the salt licks}

Sungai Papan Utara Salt Lick (X: 379428, Y: 623224). Figure 2a illustrates the physical properties surrounding the salt lick, with the vegetation distribution and composition. This salt lick comprised of two reservoirs; a hilly area with a high degree of steepness $\left(>80^{\circ}\right)$ and rocky substrates (P1), and a flat area dominated by soil (P2) (Figure 2b). The total area of the reservoir for P1 is $3 \mathrm{~m}^{2}$ while $\mathrm{P} 2$ is $4 \mathrm{~m}^{2}$. The salt lick is located near a river (approximately $1.5 \mathrm{~m}$ away). The water source for the salt lick was found oozing from the cracks and deposited in the reservoir. The vegetation density was lower compared to SPS, with only 20 plant individuals recorded in the plots. A thin layer of leaf litter covers the area on the forest floor.

Sungai Papan Selatan Salt Lick (X: 379490, Y: 622427). Figure 3a illustrates the physical properties of the SPS salt lick. The total area of the salt lick is $18 \mathrm{~m}^{2}$ and located close to a hilly area with a high degree of steepness $\left(>80^{\circ}\right)$. The reservoir is dominated by muddytexture soil that forms a distinct puddle (Figure $3 \mathrm{~b}$ ). The steep landscape within $10 \mathrm{~m}$ radius from the reservoir, is overgrown by small-sized trees $(2-17 \mathrm{~cm} \mathrm{DBH})$ with medium height $(10-25 \mathrm{~m})$. Each of the subplots at this salt lick is covered by at least 7 plant individuals and up to a maximum of 11 individuals. However, no plant species are observed on the salt lick reservoir itself. The nearest point to the river is $4 \mathrm{~m}$. The vegetation is denser with no canopy cover accompanying, with only a small number of shrubs and also covered by a thin layer of leaf litter on the forest floor.

\section{Flora diversity at the surrounding area of salt licks}

About 37 species of plants from 23 families were identified within the plots established at SPU, with less forest floor vegetation surrounding the salt lick, compared to trees. Some
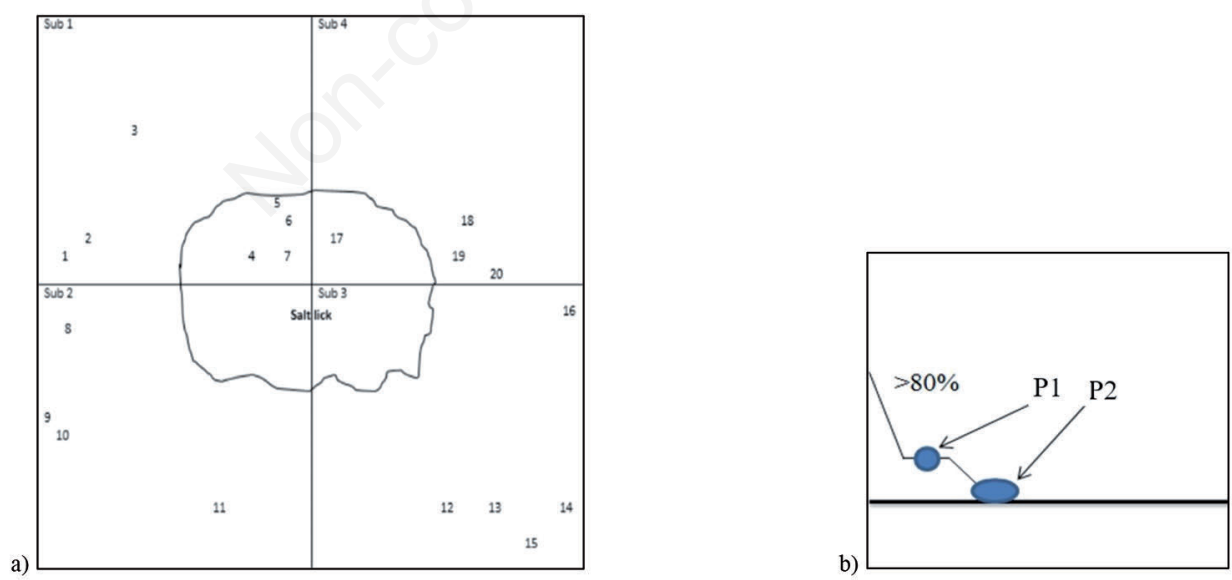

Figure 2. a) Position of plant individuals divided into 4 subplots, b) illustration of reservoir and steepness of the slope at SPU.

Note: 1. Pometia pinnata, 2. Shorea macroptera, 3. Shorea macroptera, 4. Indet. 3, 5. Artocarpus lanceifolius, 6. Cynometra malaccensis, 7. Callicarpa sp., 8. Dipterocarpus baudii, 9. Maesa ramentacea, 10. Antidesma cuspidatum, 11. Leea indica, 12. Shorea macroptera, 13. Shorea macroptera, 14. Shorea macroptera, 15. Ficus hispida, 16. Antidesma cuspidatum, 17. Baccaurea brevipes, 18. Antidesma stipulare, 19. Instia palembanica, and 20. Antidesma cuspidatum. 
small trees and shrubs grew in the salt lick such as Artocarpus lanceifolius, Cynometra malaccensis, Callicarpa sp., and Baccaurea brevipes. Common riverbank communities such as Ficus hispida, Antidesma cuspidatum, and Antidesma stipulare are abundant, as the salt lick is located near the river. Medium and large trees are dominated by Shorea macroptera and other trees such as B. brevipes, Dipterocarpus baudii, Pometia pinnata, and Intsia palembanica growing sparsely around the salt lick. A highly diverse community of medium and large trees provided a defined canopy surrounding the salt lick. Two individuals that can only be identified up to the family level due to the incomplete morphological structure were Euphorbiaceae (Indet 3) and Urticaceae (Indet 6). The details on vegetation at SPU is presented in Table $\mathrm{S} 1$.

At SPS, 62 species of plants from 37 families were recorded within the established plot, with more forest floor vegetation and trees growing in abundance and close to each other. The high density of forest floor compared to trees indicated an open canopy cover. Shorea macrantha dominated the area for medium to large trees group and other trees such as Drypetes longifolia, Horsfieldia superba, Chisocheton macrophyllus ssp., B. brevipes, Canarium littorale, and Artocarpus elasticus were also observed. On the other hand, shrubs were mainly dominated by Leea indica followed by Scolopia macrophylla and Aporosa arborea. Despite a distance of $4 \mathrm{~m}$ from the river, some riverine flora was also found around the salt lick such as Syzygium palida, Syzygium polyanthum, and Ficus fistulosa. Compared to SPU, this salt lick exhibited a higher composition of herbs and ferns due to the muddy

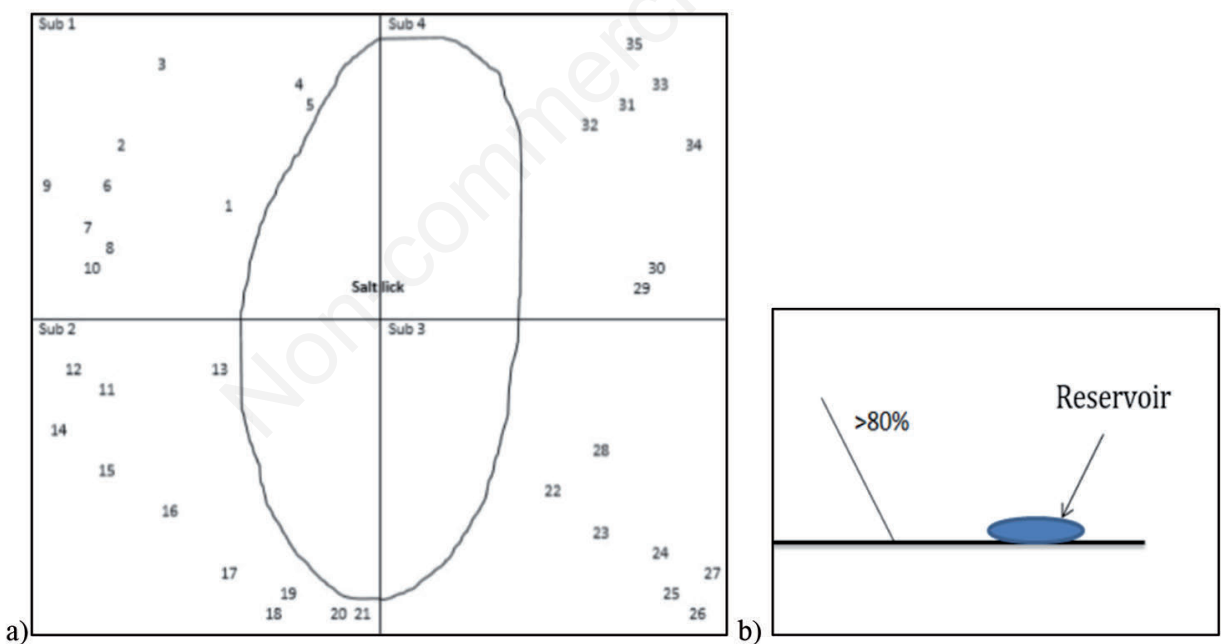

Figure 3. a) Position of plant individuals divided into 4 subplots, b) illustration of reservoir and steepness of the slope at SPS.

Note: 1. Scolopia macrophylla, 2. Syzygium palida, 3. Shorea macrantha, 4. Syzygium polyanthum, 5. Shorea macrantha, 6. Shorea macrantha, 7. Scolopia macrophylla, 8. Aporosa arborea, 9. Euonymus javanicus, 10. Aporosa arborea, 11. Scolopia macrophylla, 12. Polyalthia clavigera, 13. Leea indica, 14. Drypetes longifolia, 15. Horsfieldia superba, 16. Aporosa arborea, 17. Chisocheton macrophylla ssp., 18. Saurauia rubens, 19. Baccaurea brevipes, 20. Leea indica, 21. Leea indica, 22. Leea indica, 23. Saurauia rubens, 24. Rinorea angulate, 25. Aporosa aurea, 26. Canarium littorale, 27. Syzygium sp., 28. Leea indica, 29. Licania splendens, 30. Horsfieldia punctatifolia, 31. Ficus fistulosa, 32. Leea indica, 33. Artocarpus elasticus, 34. Bauhinia bidentata var. breviflora, and 35. Scolopia macrophylla. 
soil, indicating a high level of humidity in this area. Four individuals that can only be identified up to the family level due to the incomplete morphological structure were Apocynaceae (Indet 1), Campanulaceae (Indet 2), Gesnariaceae (Indet 4), and Poaceae (Indet 5). The details of vegetation for SPU and SPS are shown in Table S1.

Overall, there were 90 species of plants from 41 families identified within the plots established in the salt licks. Ten species were found to exist in both plots, with six species existing as forest floor vegetation at both sites, namely Homalomena sp., Schismatoglottis sp., Licuala sp., Bolbitis sp., Clidemia hirta, and trees of Indet 6. L. indica was found in both study areas, while $A$. lanceifolius exist as trees in SPU and as forest floor vegetation in SPS. Syzygium sp. exists as forest floor vegetation in SPU and as trees in SPS, while B. brevipes were found as trees in SPU and as both trees and forest floor vegetation in SPS. Altogether, SPS encompassed higher vegetation stands $(n=62)$ compared to SPU $(n=37)$, and both sites were dominant with trees and herbs. SPU was exceptionally high with trees and climbers compared to SPS with a higher proportion of understorey vegetation, namely shrubs, herbs, and ferns. Table 1 lists the number of vegetation stands based on the vegetation type.

\section{Wildlife diversity and frequency of visitation at the salt licks}

Results from camera trappings revealed a total of 21 species identified from 361 images captured at both salt licks (Table 2). Out of all the 21 species, two of them are listed as Near Threatened, four as Vulnerable, and three as Endangered by IUCN Red List of Threatened Species. The three species listed as Endangered were Tapirus indicus, Elephas maximus, and Trachypithecus obscurus. From these numbers, 14 species were salt-lick users (indicated in asterisks), whereas the others were visiting or passing by. Wildlife visitation frequency was significantly different between SPU and SPS (Mann-Whitney U, Z $=-2.469, \mathrm{p}<0.1$ ), with higher frequency in SPS (242 individuals) compared to SPU (119 individuals).

The visitors of SPU salt lick comprised of 18 species, 16 families, and 10 orders, with Cervidae being the most dominant representing $14.4 \%$ of all the images captured. This is followed by Suidae (3.3\%), Hystricidae (3.0\%), Cercopithecidae (3.05\%), Tapiridae (2.7\%), Muscicapidae (2.2\%), Canidae (0.8\%), Elephantidae $(0.5 \%)$, Columbidae $(0.5 \%)$, Muridae (0.5\%), and $0.2 \%$ of Tragulidae, Felidae, Mustelidae, Herpestidae, Varanidae, and Accipitridae. Muntiacus muntjak was found to be the most frequent visitor at this salt lick, with 52 visitations. SPS, on the other hand, recorded 7 species, 7 families, and 6 orders of wildlife. Similar to SPU, Cervidae is the most dominant family, representing $39.6 \%$ of all the images. This is followed by Suidae (23.5\%), Hystricidae (1.6\%), Ursidae (0.5\%), and

Table 1. Number of vegetation stands (\%) at both salt licks sites.

\begin{tabular}{lcc} 
Types & SPU $(\%)$ & SPS $(\%)$ \\
Tree & $17(45.9)$ & $26(41.9)$ \\
\hline Small Tree & $1(2.7)$ & $2(3.2)$ \\
\hline Woody Climber & $0(0)$ & $1(1.6)$ \\
\hline Climber & $4(10.8)$ & $3(4.8)$ \\
\hline Palm & $2(5.4)$ & $4(6.5)$ \\
\hline Shrub & $3(8.1)$ & $6(9.7)$ \\
\hline Herb & $8(21.6)$ & $17(27.4)$ \\
\hline Fern & $2(5.4)$ & $3(4.8)$ \\
\hline Total tree stands & 37 & 62
\end{tabular}


$0.1 \%$ of Elephantidae and Phasianidae. Similar to SPU, M. muntjak also exhibited the highest visitation frequency in SPS. On another note, nine species were only found visiting the salt lick once, including Tragulus kanchil, Macaca nemestrina, T. obscurus, Prionailurus bengalensis, Lutrogale perspicillata, Herpestes urva, Varanus salvator, Gallus gallus, and Nisaetus cirrhatus at any salt licks. Altogether, $96.5 \%$ of the recorded species were mammals, $3.3 \%$ avian, and $0.2 \%$ reptiles.

Table 2. Frequency of wildlife visitation at each salt licks.

\begin{tabular}{|c|c|c|c|c|c|}
\hline Order/Family & Species & SPU & SPS & $\begin{array}{l}\text { IUCN } \\
\text { Status }\end{array}$ & $\begin{array}{l}\text { Diet } \\
\text { type }\end{array}$ \\
\hline \multicolumn{6}{|c|}{ ARTIODACTYLA } \\
\hline Suidae & Sus scrofa (Linnaeus, 1758)* & 12 & 85 & $\mathrm{LC}$ & $\mathrm{O}$ \\
\hline \multirow[t]{2}{*}{ Cervidae } & Muntiacus muntjak (Zimmermann, 1780)* & 52 & 143 & $\mathrm{LC}$ & $\mathrm{HF}$ \\
\hline & Rusa unicolor (Kerr, 1792)* & 0 & 4 & VU & $\mathrm{HF}$ \\
\hline Tragulidae & Tragulus kanchil Raffles, 1821* & 1 & 0 & $\mathrm{LC}$ & $\mathrm{HF}$ \\
\hline \multicolumn{6}{|c|}{ PERISSODACTYLA } \\
\hline Tapiridae & Tapirus indicus Desmarest, 1819* & 10 & 0 & $\mathrm{EN}$ & $\mathrm{HF}$ \\
\hline \multicolumn{6}{|c|}{ PROBOSCIDEA } \\
\hline Elephantidae & Elephas maximus Linnaeus, $1758^{*}$ & 2 & 1 & EN & $\mathrm{HF}$ \\
\hline \multicolumn{6}{|c|}{ PRIMATES } \\
\hline \multirow[t]{4}{*}{ Cercopithecidae } & Macaca nemestrina (Linnaeus, 1766)* & 1 & 0 & VU & $\mathrm{O}$ \\
\hline & Presbytis siamensis (Müller \& Schlegel, 1841)* & 9 & 0 & NT & $\mathrm{HF}$ \\
\hline & Trachypithecus obscurus (Reid, 1837)* & 1 & 0 & $\mathrm{EN}$ & $\mathrm{HF}$ \\
\hline & \multicolumn{5}{|l|}{ RODENTIA } \\
\hline Hystricidae & Hystrix brachyura Linnaeus, 1758* & 11 & 6 & $\mathrm{LC}$ & $\mathrm{HF}$ \\
\hline Muridae & Rattus sp.* & 2 & 0 & - & $\mathrm{O}$ \\
\hline \multicolumn{6}{|c|}{ CARNIVORA } \\
\hline Felidae & Prionailurus bengalensis (Kerr, 1792) & 1 & 0 & $\mathrm{LC}$ & $\mathrm{C}$ \\
\hline Canidae & Canis lupus familiaris Linnaeus, 1758 & 3 & 0 & - & $\mathrm{C}$ \\
\hline Ursidae & Helarctos malayanus (Raffles, 1821) & 0 & 2 & VU & $\mathrm{O}$ \\
\hline Mustelidae & Lutrogale perspicillata (I. Geoffroy Saint-Hilaire, 1826) & 1 & 0 & VU & $\mathrm{C}$ \\
\hline Herpestidae & Herpestes urva (Raffles, 1821) & 1 & 0 & $\mathrm{LC}$ & $\mathrm{C}$ \\
\hline \multicolumn{6}{|c|}{ SQUAMATA } \\
\hline Varanidae & Varanus salvator (Laurenti, 1768) & 1 & 0 & $\mathrm{LC}$ & $\mathrm{C}$ \\
\hline \multicolumn{6}{|c|}{ COLUMBIFORMES } \\
\hline Columbidae & Chalcophaps indica Linnaeus, 1758* & 2 & 0 & $\mathrm{LC}$ & $\mathrm{F}$ \\
\hline \multicolumn{6}{|c|}{ PASSERIFORMIES } \\
\hline Muscicapidae & Enicurus ruficapillus Temminck, 1823* & 8 & 0 & NT & I \\
\hline \multicolumn{6}{|c|}{ GALLIFORMES } \\
\hline Phasianidae & Gallus gallus (Linnaeus, 1758)* & 0 & 1 & $\mathrm{LC}$ & G \\
\hline \multicolumn{6}{|c|}{ ACCIPITRIFORMIES } \\
\hline Accipitridae & Nisaetus cirrhatus (Gmelin, 1788) & 1 & 0 & $\mathrm{LC}$ & $\mathrm{C}$ \\
\hline Total & & 119 & 242 & & \\
\hline
\end{tabular}


The Shannon diversity index of wildlife at SPU was higher, with 2.01 compared to 0.92 in SPS. On the other hand, SPS has a higher species dominancy $(0.47)$ compared to SPU (0.23). A higher level in dominance usually indicates a low evenness in species distribution. This is proven with SPS having a lower evenness value (0.36) compared to SPU. Finally, by using Chao-1 estimator with more sampling effort, SPU could yield a total of 25 species compared to 18 species currently recorded, whereas SPS could potentially increase to 7.5 species compared to the currently observed value of 7 species. This suggests that more species could be obtained in SPU, but SPS almost reached an accumulated species number.

Wildlife visiting both salt licks were assigned to six feeding guilds, with the HF type being the most dominant ( 240 individuals, 8 species), followed by omnivore (102 individuals, 4 species), and carnivore ( 8 individuals, 6 species). Insectivore, frugivore, and granivore were recorded only occasionally. From these, carnivore visits were significantly different at both sites (Mann-Whitney $U, Z=-3.07, p=0.02$ ), with an only presence at SPU salt lick. Canis lupus familiaris was the dominant carnivorous species recorded, other than P. bengalensis, L. perspicillata, and H. urva from the family Canidae and N. cirrhatus from the family Accipitridae. HF and omnivore visit did not show significant differences at both salt licks $(\mathrm{p}>0.05)$.

PCA revealed two components with eigenvalues that explained $75.8 \%$ and $24.2 \%$ of the total variance, respectively. Marked differences in species distribution are noted in the PCA case scores biplot (Figure 4), according to diet types at both SPU and SPS. A more diverse species assemblage is present at SPU compared to SPS, which consists of different feeding types, including carnivore, frugivore, herbivore-frugivore, insectivore, represented by M. muntjak, Hystrix brachyura, T. indicus, Presbytis siamensis, Enicurus ruficapillus, E. maximus, Rattus sp., and C. lupus familiaris. These species were generally found in high number in SPU, which could coincide with the lower vegetation composition, particularly forest floor vegetation. On the other hand, only a handful of species assemblage is present at SPS, particularly from the herbivore-frugivore, omnivore and granivore diet groups, represented by Rusa unicolor, Helarctos malayanus, G. gallus, and T. kanchil. They show the

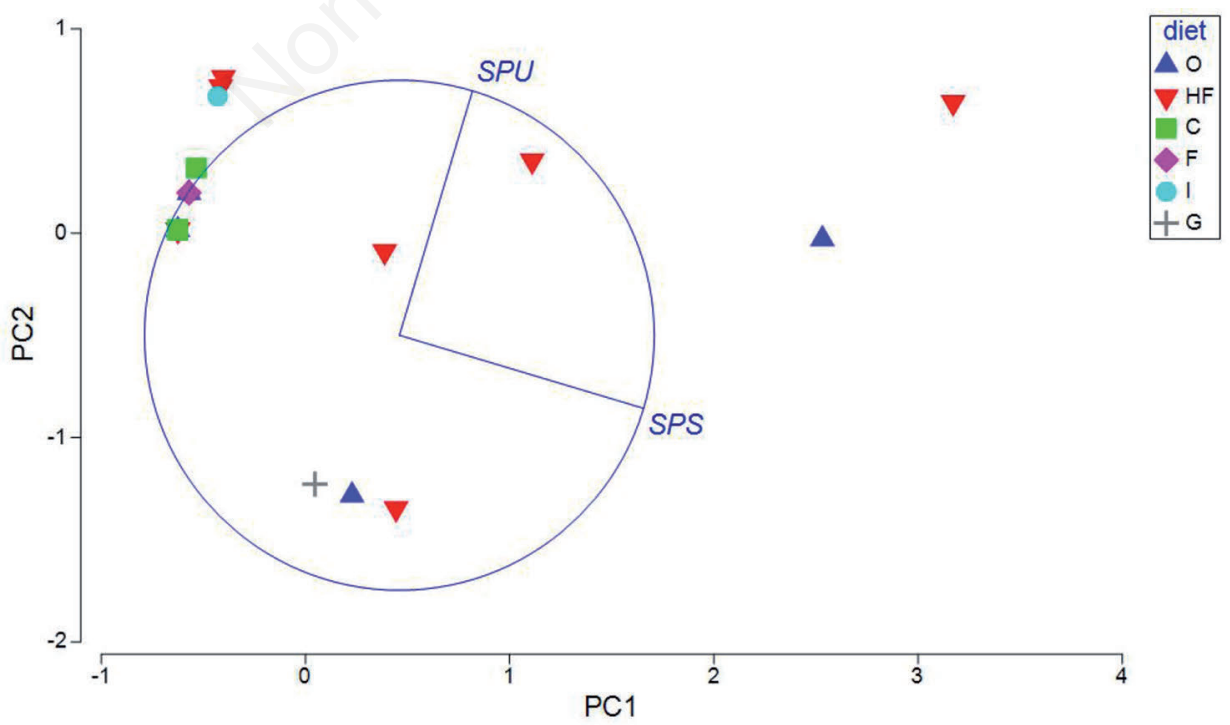

Figure 4. PCA biplot for wildlife visitation frequency based on diet types at different salt licks. 
highest frequency of visitations at SPS salt licks due to high vegetation cover and incredibly dense forest floor vegetation.

\section{Discussion and conclusions}

Consistent with other studies, the salt licks from this survey were visited by different animal species, mostly herbivores and frugivores (Matsubayashi et al. 2007; Molina et al. 2014), and usually from the mammal and avian groups (Kreulen 1985; Krishnamani and Mahaney 2000; Bravo et al. 2008). According to Blake et al. (2011), species composition and frequency of wildlife visitation at salt licks vary in terms of the mineral content, accessibility, and the topographic features of the licks, apart from habitat preference, foraging, and ranging behaviour of the animal troops. Images and footages showed that most of the visitors consisted of ungulates, primates, rodents, carnivores, Proboscidea, and Perissodactyla. The species could be identified as salt lick users and non-users. Our study revealed 14 species as salt licks users. The use of mineral licks was often associated with diets low in essential nutrients, such as sodium. Salt licks also offer other supplementary diets such as calcium, magnesium, and zinc (Moe 1993). Frugivores and herbivorous animals are known to have a diet low in sodium, which explains the need for geophagy, particularly at salt licks (Ayotte 2005; Bravo et al. 2008); hence, the high abundance of these two groups of wildlife in our study. Matsubayashi et al. (2007) reported that despite a significantly high concentration of potassium than sodium in herbivore diets, an excess of sodium excretion through urine was noted, justifying the high demand for sodium at licks among herbivores. Our study did not record high visitation among frugivores, although this group of animals consume diets low in sodium. This observation supports the findings by Blake et al. (2011) that frugivorous diet does not necessarily use salt licks for mineral supplementation. Apart from that, fruit-eating bats were demonstrated to consume salts to buffer the effects of secondary plant compounds that they ingest in large quantities during high energy demand (Voigt et al. 2018).

The non-salt lick users recorded at the natural salt licks and their surrounding mainly belonged to the carnivore and omnivore groups. Unlike herbivores and frugivores, carnivorous and omnivorous animals obtain their sodium intake direct from their prey (Matsubayashi et al. 2007), suggesting that these predators use salt licks for hunting preys that depend on the natural licks. The presence of these animal groups could also be associated with their home range or roaming areas during hunting and foraging (Matsubayashi and Lagan 2014). The less-dense vegetation could aid in the foraging of prey among carnivores due to the high visibility and ease of movement, as demonstrated among leopard cats (Rajaratnam et al. 2007) at the SPU site. In another instance, other groups of wildlife such as ungulates, rodents, Proboscidea, and Perissodactyla are known as the predators' target at salt licks, making visits inherently hazardous (Moe 1993). Thus, there is a high possibility that these animals frequent SPS for concealments from predators provided by the dense understorey vegetation. Therefore, natural salt licks are indeed important for both planteating mammals and predatory mammals as well.

The presence of arboreal species such as P. siamensis and T. obscurus only at SPU showed that higher canopy vegetation plays a vital role in their presence. Arboreal species are seldom thought to descend to the ground and are usually highly mobile through dense vegetation with high canopy (Maklarin 2008; Hambali et al. 2016). Therefore, a closed canopy due to the high emergence of tall trees surrounding salt licks would have an advantage for the arboreal species. This justifies the absence of primates from the SPS site due to the lack of high trees. 
However, the high vegetational cover in SPS benefits the herbivores, particularly ungulates, explaining their high visitation frequency to the area. Moreover, ungulates were found to prefer feeding in forest gaps instead of closed-canopy forest (Kuijper et al. 2009). For instance, $M$. muntjak and $R$. unicolor were known to browse for understorey vegetation such as shrubs and herbs (Ilyas and Khan 2003; Teng et al. 2004). These two species were known as the most common deer species in tropical Asia (Corbet and Hill 1992), and are relatively dominant wildlife species in both licks. The frequency of visits by Sus scrofa was exceptionally high in SPS, indicating the low presence of predators, as demonstrated by the absence of any carnivorous species in this area. The high population of this species in the tropical rain forest was reportedly due to the absence of feline predators and abundant all-year-round food supply of the forest (Ickes 2001). Therefore, the hyper-abundance of this species has massive implication to the dynamics of the forests due to their soil-rooting behaviour, which facilitates the spread of exotic plant into the primary forest (Peters 2001). Other behaviours include the snapping off woody saplings during nests building among female pigs (Liu et al. 1999) and reducing the local density of small terrestrial mammals (Kemper and Bell 1985). Moreover, according to camera trap images, S. scrofa and $M$. muntjac were seen together with their young. A study by Ampeng (2013) proved that groups of reproductive females and juveniles have a higher visitation frequency at the salt licks, indicating the importance of salt licks to enrich the nutrients of their young. The denser vegetation, flat surface, and absence of predators provide better security, especially for females and the young. There were no records of $T$. indicus in SPS, unlike in SPU. This species is among the primary seed dispersal agents in rainforests (Fragoso et al. 2003) and highly prefers feeding on several plant species from the family Euphorbiaceae (leaf flowers), Myristicaceae (nutmegs), and Sapindaceae (Simpson 2014), that were more readily available in SPU. Therefore, this study confirms that salt lick use by ungulates is not only a reserve for geophagy but also foraging.

Another factor that might influence the frequency of wildlife visitation at both natural salt licks is the texture and substrate of the salt lick reservoir. SPU exhibits rocky substrate, whereas SPS has a muddy texture, which allows the growth of herbs and ferns in this area. According to Molina et al. (2014), the salinity of rocky substrates exceeds muddy salt licks, suggesting that dilution effects exist at the muddy salt licks, which might explain the differences in wildlife composition in our study. The muddy substrate could easily wash away the minerals during the wet season or rainfalls, but a more in-depth look on this regard is needed. In general, regardless of their physical properties, salt licks are important local wildlife hotspots, and this study emphasises the need to prioritise conservation areas by maximising the complementarities of salt licks. Information on the vegetation composition is also helpful in the management of the natural salt licks and in designing artificial ones. A detailed study on the chemical properties of salt licks is deemed necessary to further understand their mineral compounds in order to protect and manage salt licks for wildlife conservation in the Royal Belum State Park rainforest in particular and tropical rainforests in general. This study also provides a useful guideline to be considered for effective artificial salt licks design.

\section{Acknowledgements}

We want to thank wildlife rangers and staff of Perak State Park Cooperation (PSPC), particularly Mr. Safri Muhiyuddin, as well as the Universiti Kebangsaan Malaysia (UKM) staff for their assistance during commencement of the fieldwork. The Department of 
Wildlife and National Park (DWNP) and Perak State Park Cooperation (PSPC) are also acknowledged for granting research permits.

\section{Funding}

This project was funded by Tenaga Nasional Berhad Research (TNBR) under research code ST-2018-008.

\section{Conflict of interest}

We declare that there is no conflict of interest.

\section{Authors' contributions}

NBR, MSHS, RAMJ and SHAR performed the wildlife sampling, NHAK and SK the flora sampling, FSM-T, SMN and EN the design of the study and interpretation of data. All of the above authors contributed to the writing of the manuscript. SHAR, SMH and MSR represent relevant authorities who assisted in the execution of the study.

\section{References}

Ampeng A. 2013. Ecology and importance of mineral licks to wildlife in Lanjak Entimau Wildlife Sanctuary, Sarawak. Unpublished PhD Thesis. The National University of Malaysia, Malaysia.

Ayotte JB. 2005. Ecological importance of licks to four ungulates in north central British Columbia. Unpublished Master ThesisUniversity of Northen British Columbia, Canada.

Blake JG, Mosquera D, Guerra J, Loiselle BA, Romo D, Swing K. 2011. Mineral licks as diversity hotspot in lowland forest of Eastern Ecuador. Diversity. 3:217-234.

Bravo A, Harms KE, Stevens RD, Emmons LH. 2008. Activity hotspots for frugivorous bats (Phyllostomidae) in the Peruvian Amazon. Biotropica. 40(2):203-210.

Burton AC, Neilson E, Moreira D, Ladle A, Steenweg R, Fisher JT, Erin B, Boutin S. 2015. Wildlife camera trapping: a review and recommendation for linking surveys to ecological processes. Journal of Applied Ecology. 52:675-685.

Chuan AS, Weng CN, Mapjabil J. 2012. Salt licks and adventurous tourists: A framework for sustainable ecotourism. Geografia - Malaysian Journal of Society and Space. 5: 76-93.

Corbet GE, Hill JE 1992. The mammals of the Indomalayan region. Oxford: Oxford University Press. $\mathrm{VI}+488 \mathrm{pp}$.

De Bondi N, White JG, Stevens M, Raylene C. 2010. A comparison of the effectiveness of camera trapping and live trapping for sampling terrestrial small mammal communities. Wildlife Research. 37: 456-465.

Dudley R, Michael K, Stephen PY. 2012. Lust for salt in the Western Amazon. Biotropica. 44:6-9.

Fragoso JMV, Silvius KM, Correa JA. 2003. Long $\square$ distance seed dispersal by tapirs increases seed survival and aggregates tropical trees. Ecology. 84(8):1998-2006.

Francis CM. 2008. A Field Guide to The Mammals of South-East Asia. 2nd Ed. London: New Holland Publisher. 392 pp.

Gomez-Hoyos D, Gonzalez-Maya JF, Pacheco J, Seisdedos-Vegara R, Barrio-Amoros CL, Gerardo C. 2017. Mineral -Licks use by Choloepus hoffmanni (Pilosa: Megalonychidae) at Las Cruces Biological Station, Coto Brus, Costa Rica. The Southwestern Naturalist. 62: 278-280.

Hambali K, Md-Zain BM, Amir A. 2016. Daily movement, sleeping sites and canopy level use of habituated silvered-leaf monkeys (Trachypithecus cristatus) in Bukit Malawati, Kuala Selangor, Malaysia. Journal of Sustainability Science and Management. 11:21-30. 
Hon J, Shibata S. 2013. Temporal partitioning by animals visiting salt licks. International Journal of Environmental Science and Development. 4:44-48.

Ickes K. 2001. Hyper-abundance of native wild pigs (Sus scrofa) in a lowland Dipterocarp Rain Forest of Peninsular Malaysia. Biotropica. 33(4):682-690.

Ilyas O, Khan JA. 2003. Food habits of barking deer (Muntiacus muntjak) and goral (Naemorhedus goral) in Binsar Wildlife Sanctuary, India. Mammalia. 67:521-531.

Izsák J, László P. 2000. A link between ecological diversity indices and measures of biodiversity. Ecological Modelling. 30(3):151-156.

Kemper C, Bell DT. 1985. Small mammals and habitat structure in lowland rain forest of Peninsular Malaysia. Journal of Tropical Ecology. 1: 5-22.

Keylock CJ. 2005. Simpson diversity and the Shannon-Wiener index as special cases of generalised entropy. Oikos. 109:203-207.

Klaus G, Klaus-Hugi C, Schmid B. 1998. Geophagy by large mammals at natural licks in the rain forest of the Dzanga National Park, Central African Republic. Journal of Tropical Ecology. 14: 829-839.

Kreulen DA. 1985. Lick use by large herbivores: a review of benefits and banes of soil consumption. Mammal Review. 15:107-123.

Krishnamani R, Mahaney WC. 2000. Geophagy among primates: Adaptive significance and ecological consequences. Animal Behaviour. 59: 899-915.

Kuijper DPJ, Cromsigt JPGM, Churskia M, Adam B, Jędrzejewska B, Jędrzejewski W. 2009. Do ungulates preferentially feed in forest gaps in European temperate forest? Forest Ecology and Management. 258(7):1528-1535.

Li W, Li C, Jiang Z, Guo R, Ping X. 2018. Daily rhythm and seasonal pattern of lick use in sika deer (Cervus nippon) in China. Biological Rhythm Research. 3:1-10.

Liu J, Ickes K, Ashton PS, La Frankie JV, Manokaran N. 1999. Spatial and temporal impacts of adjacent areas on the dynamics of species diversity in a primary forest. In: Mladenoff D, Baker W., editors. Spatial modelling of forest landscape change. Cambridge, England: Cambridge University Press. , p. 42-69.

Lizcano DJ, Cavelier J. 2004. Chemical characteristics of salt licks and feeding habits of mountain tapir (Tapirus pinchaque) in the Central Andes of Colombia. Maztozoologia Neotropical. 11:193-201.

Maklarin L. 2008. Comparative ecology of sympatric Presbytis rubicunda and Macaca fascicularis in Tawau Hills Park, Sabah. Unpublished PhD Thesis.Universiti Malaysia Sabah, Malaysia.

Matsubayashi H, Lagan P. 2014. Natural salt-licks and mammals in Deramakot: their importance and why they should be conserved. Sandakan: Sabah Forestry Department.

Matsubayashi H, Lagan P, Majalap N, Tangah J, Sukor JRA, Kitayama K. 2007. Importance of natural licks for the mammals in Bornean inland tropical rain forests. Ecological Research. 22: 742-748.

Moe SR. 1993. Mineral content and wildlife use of soil licks in southwestern Nepal. Canadian Journal of Zoology. 71: 933-936.

Molina E, León TE, Armenteras D. 2014. Characteristics of natural salt licks located in the Colombian Amazon foothills. Environmental Geochemistry and Health. 36:117-129.

Panichey AM, Olga YU, Zaumyslova U, Aramiley VV. 2002. The importance of salt licks and other sources of sodium in the ecology of the Ussuri moose (Alces alces cameloides). Alces. 38:55-60.

Peters H. 2001. Clidemia hirta invasion at the Pasoh Forest Reserve: an unexpected plant invasion in an undisturbed tropical forest. Biotropica. 33:60-68.

Ping X., Li C, Jiang Z, Liu W, Zhu H. 2011. Sexual difference in seasonal patterns of salt lick use by South China sika deer Cervus nippon. Mammalian Biology - Zeitschrift für Säugetierkunde. 76:196-200.

Rajaratnam R, Sunquist M, Rajaratnam L, Ambu L. 2007. Diet and habitat selection of the leopard cat (Prionailurus bengalensis borneoensis) in an agricultural landscape in Sabah, Malaysia Borneo. Journal of Tropical Ecology. 23:209-217.

Simpson BK, Md Nor S, Magintan D. 2014. Food selection of the Malayan tapir (Tapirus indicus) under semi-wild conditions. The 2013 UKM FST Postgraduate Colloquium. AIP Conference Proceedings. 1571(1): 317-324.

Sitienei AJ, Ji WG, Shadrack MN, Mupenzi JDLP, Fred W. 2012. Analysis in the concentration, de- 
termination and comparison of some mineral elements in the natural salt licks utilised by elephants: Mt. Elgon National Park Case Study. Advanced Materials Research. 356:1796-1800.

Tankersley NG, Gassaway CW. 1983. Mineral lick use by moose in Alaska. Canadian Journal of Zoology. 61:2242-2249.

Teng L, Liu Z, Songi YL, Zengi Z. 2004. Forage and bed sites characteristics of Indian muntjac (Muntiacus muntjak) in Hainan Island, China. Ecological Research. 19:675-681.

Turner IM 1995. A catalogue of the vascular plat of Malaya. Garden's Bulletin Singapore. 47(1):1-757.

Tobler MW, Carrillo-Percastergui SE, Powell G. 2009. Habitat use, activity patterns and use of mineral licks by 5 species of ungulate in South-Eastern Peru. Journal of Tropical Ecology. 25:261-270.

Voigt CC, Capps KA, Dechmann DKN, Michener RH, Kunz TH. 2008. Nutrition or detoxification: why bats visit mineral licks of the Amazonian Rainforest. PLoS ONE. 3(4):e2011.

Weeks HP. 1978. Characteristics of mineral licks and behaviour of visiting white-tailed deer in southern Indiana. The American Midland Naturalist Journal. 100: 384-395. 